\title{
RFID Systems Composed of Multiband Antenna with Fractal Geometry
}

\author{
Chitra Varadhan ${ }^{1}$, Dr.S.Arulselvi ${ }^{2}$ \\ \{chitralaya@gmail.com ${ }^{1}$, arulselvi2003@gmail.com² ${ }^{2}$. \\ Research Scholar, Departmentof ECE, Bharath Institute of Higher Education and Research, Chennai, \\ Tamilnadu, India - $600073^{1}$, \\ Associate Professor, Departmentof ECE, Bharath Institute of Higher Education and Research, \\ Chennai, Tamilnadu, India - $600073^{2}$
}

\begin{abstract}
Two tri-band RFID tag and reader antennas are proposed in this paper. The primary aim of the proposed work isto achieve multi-band antennas by implementing fractal designs as radiating elements. The RFID reader antenna is createdby using modified fractal tree structure; the operating frequencies are $3.6 \mathrm{GHz}, 5.8 \mathrm{GHz}$, and 8.2 GHz. The recursive rectangular is implemented in RFID tag antenna operates at $3.9 \mathrm{GHz}$, $5.9 \mathrm{GHz}$, and $8.2 \mathrm{GHz}$ for the RFID applications of goods management, traffic toll fee collection, telemetry respectively. The proposed reader antenna achieved a highest read range of $87.5 \mathrm{~cm}$ and tag antenna accomplished $85.6 \mathrm{~cm}$.
\end{abstract}

Keywords: Multiband, Fractals, Radio Frequency Identification (RFID), Co-planar Wave Guide (CPW), Antenna.

\section{Introduction}

The Radio Frequency Identification (RFID) is an essential technology in a real world scenario. RFID is availed in Inventory Tracking, Attendee tracking and recording, Materials management, i.e., keeping tracking of goods, logistics transportation, and traffic toll fee collection [1]. The design of antenna is usually the bottleneck of a RFID reader and tag systems. It is operated at a variety of radio frequencies. Each and every country follows distinct frequencies for various applications. Different stages of antenna design, requires attention to issues like miniaturization of size, reduction in cost and performance improvisation. Therefore, design and implementation of a compact single antenna operating at multiple frequencies is a great challenge.

The aim of this antenna design is to managing the RFID reader applications. Next antenna is especially made for RFID tag application. The construction of reader and tag antennas are deployed from binary fractal tree structure and recursive rectangles respectively. The paper describes the design of fractal iteration in forthcoming modules. The RFID reader antenna design is fundamentally a dipole antenna, with few modifications. The proposed fractal antennas operate in SHF (Super High Frequency) range i.e., $3 \mathrm{GHz}$ to $30 \mathrm{GHz}$, predominately used for high speed detection. As per theory, when frequency increases, the travel time for the signal decreases proportionally. From the literature survey, it is observed that the SHF RFID object moves at a maximum up to $145 \mathrm{Km} / \mathrm{h}$ speed [2]. Therefore, essentially it is required in RFID goods management, RFID traffic toll fee collection and RFID telemetry purpose, where 
the collection of data is required while object are in move and also the size of antenna is small and sufficient to affix on logistics goods as well as attachable onto employee ID cards. The proposed antenna for the tag operation is also of unique construction with fractal design.

Fractal structures used in RFID systems are proposed for implementation based on space filling and self-similarity properties. Self-similarity property is to increase the electrical length of material that can transmit or receive the electromagnetic emission within a stipulated volume. By designing multiple numbers of dipole arms at a single surface, certain classes of fractal antennas can be used to operate effectively at different frequency bands (multiband). In fractal structures, the space-filling property is implemented for reducing the antenna size, while increasing the perimeter of the antenna within the given area.

This paper provides antenna design details and explores the RFID antenna simulation results in transient solver using EM design software. The attained results are compared with frequency domain solver and fabricated after obtaining adequate results. The fabricated prototype performance is measured with Vector Network Analyzer subsequently; the measured results are analyzed with simulated results.

\section{Proposed Fractal Structure}

Fractals are obtained by surface transformation such that it can be used as radiating elements. The fractal design is acquired from the elemental transformation of structures [3]. These may be a line, or surface or a volume of material and fractal structure can be derived.

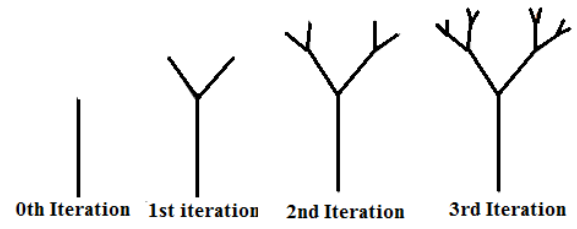

Figure. 1. Proposed antenna design stages of RFID Reader

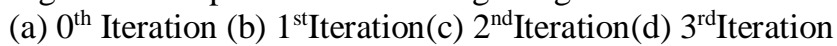

The various design stages of a binary fractal tree as depicted by Figure 1, are commonly made such that the angle encompassed between the twigs of all the stem is a constant. A modified binary fractal tree structure is proposed (Figure 1(a)), with the angle between the bifurcating twigs reduced by half in every iteration, resulting in miniaturization of fractal geometries that contain increased electrical lengths in a definite physical area. Further conformal, multi-band and low profile with broadband antennas are achieved for RFID system $[4,5]$.Recursive rectangular configuration is proposed for the second antenna applicable in RFID tag operation. Figure 2 indicates proposed design iterations of the RFID tag antenna. 


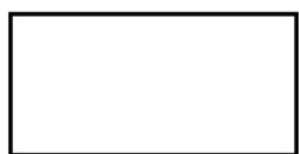

0th Iteration

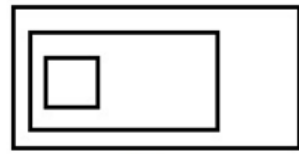

2nd Iteration

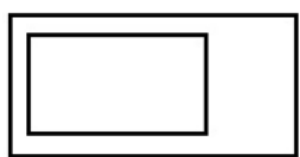

1st iteration

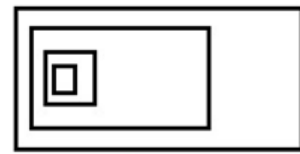

3rd Iteration

Figure. 2. Proposed Antenna Design for RFID Tag

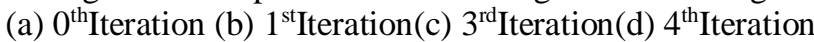

\section{Design of RFID Antennas}

\section{a) RFID Reader antenna}

The literature survey details the integrations of multi-band in to a single plane using CoPlanar Waveguide Structure (CPW)[6 \&7]. The outcome of introducing a secondary strip or slot, produces an additional band and good electrical properties are obtained by fractal design. The diagrammatic representation of the proposed RFID reader antenna is demonstrated in Figure 3.

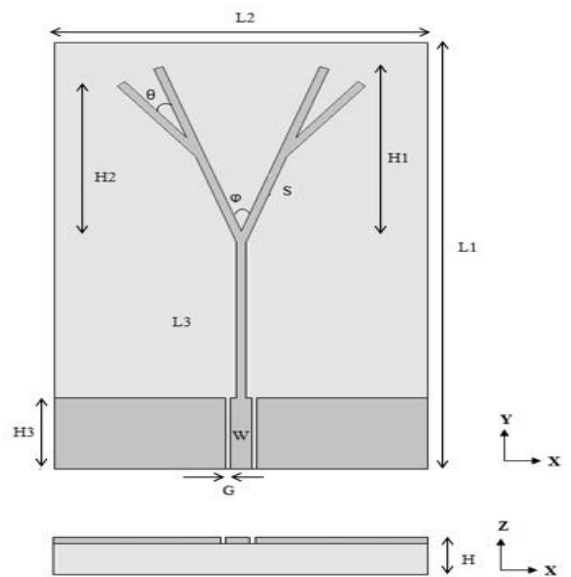

Figure. 3. Proposed RFID reader antenna using modified fractal tree structure, with CPW feed.

The reader antenna is designed on a substrate (FR4 lossy) with a $1.6 \mathrm{~mm}$ thickness (loss tangent $=0.025$ and relative dielectric constant $=4.3$ ) and is fed by $50 \Omega$ coaxial connector. The complete substrate dimension is $40 \mathrm{~mm}$ x $60 \mathrm{~mm}$. The designed resonating three frequencies of the antenna are $\mathrm{f}_{1}=3.6 \mathrm{GHz}, \mathrm{f}_{2}=5.7 \mathrm{GHz}$, and $\mathrm{f}_{3}=8.2 \mathrm{GHz}$. The dimensions of the antenna are $\mathrm{H}=1.6 \mathrm{~mm}, \mathrm{H}_{1}=23 \mathrm{~mm}, \mathrm{H}_{2}=21 \mathrm{~mm}, \mathrm{H}_{3}=10 \mathrm{~mm}, \mathrm{~L}_{1}=60 \mathrm{~mm}, \mathrm{~L}_{2}=40 \mathrm{~mm}$, $\mathrm{L}_{3}=22 \mathrm{~mm}, \mathrm{~S}=1 \mathrm{~mm}, \mathrm{~W}=2.2 \mathrm{~mm}, \mathrm{G}=0.5 \mathrm{~mm} \theta=20^{\circ}, \varphi=40^{\circ}$ 


\section{b) RFID Tag Antenna}

The proposed RFID tag antenna geometry is illustrated in Figure 4. A $50 \Omega$ coaxial connector is fed on a designed FR4 substrate with $1.6 \mathrm{~mm}$ thickness. The dimension of the antenna substrate is measured as $90 \mathrm{~mm} \times 30 \mathrm{~mm}$. In the RFID tag the feeding structure is the critical design part. The CPW feeding method [8] provides the freedom to use either the SMA connector orchip based and further tested via a VNA. The designed operating frequencies of the tag antenna are $\mathrm{f}_{1}=3.9 \mathrm{GHz}, \mathrm{f}_{2}=5.9 \mathrm{GHz}$ and $\mathrm{f}_{3}=8.2 \mathrm{GHz}$ respectively. The antenna dimensions are $S_{1}=1.6 \mathrm{~mm}, \mathrm{~S}=1 \mathrm{~mm}, \mathrm{~W}=2.4 \mathrm{~mm}, \mathrm{~L}_{1}=90 \mathrm{~mm}, \mathrm{~L}_{2}=30 \mathrm{~mm}, \mathrm{~L}_{3}=10 \mathrm{~mm}, \mathrm{G}=$ $1 \mathrm{~mm}$. Figure 4 demonstrates the parameters corresponding to the measurements of the designed antenna.

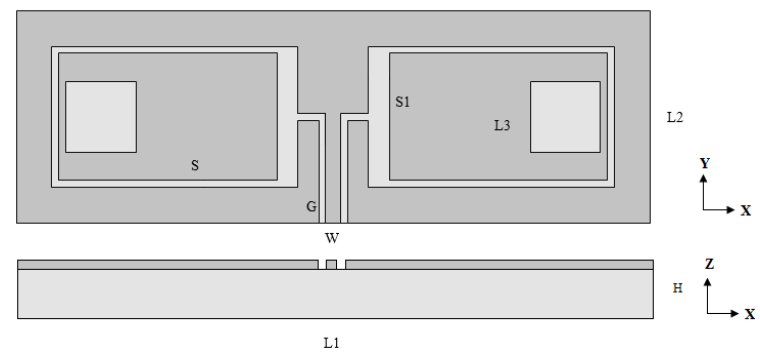

Figure. 4. Proposed RFID Tag antenna using recursive rectangular structure, with CPW feed

\section{Results and Discussions}

\section{a) Reader antenna}

The simulated results of $\mathrm{S}_{11}$ characteristics in time and frequency domain solvers of reader antenna are compared in Figure 5. The experimental results of the antenna operate at three different frequencies $\mathrm{f}_{1}, \mathrm{f}_{2}$, and $\mathrm{f}_{3}$. The first frequency $\mathrm{f}_{1}$ operates at $3.6 \mathrm{GHz}$, whose return loss value $\left(\mathrm{S}_{11}\right)$ is $-19.41 \mathrm{~dB}$ and the corresponding bandwidth is $(-10 \mathrm{~dB})$ obtained at $248 \mathrm{MHz}$ and thepercentage bandwidth is 6.89 . The subsequent occurrence is $5.7 \mathrm{GHz}$ and detected $\mathrm{S}_{11}$ value of $-20.38 \mathrm{~dB}$, the bandwidth $(-10 \mathrm{~dB})$ obtained at $398 \mathrm{MHz}$ with a7.1 percentage bandwidth. The final frequency is falls in $8.2 \mathrm{GHz}$, an $\mathrm{S}_{11}$ parameter of $-20.63 \mathrm{~dB}$ with a bandwidth $(-10 \mathrm{~dB})$ at $405 \mathrm{MHz}$ and the corresponding bandwidth percentage is 4.96 .

The obtained VSWR (measured @ VSWR=2) is given as $336 \mathrm{MHz}$ for $\mathrm{f}_{1}, 423 \mathrm{MHz}$ for $\mathrm{f}_{2}$ and $433 \mathrm{MHz}$ at $\mathrm{f}_{3}$ and the corresponding $\mathrm{E}$ and $\mathrm{H}$ plane field pattern of the reader antenna is exhibited in Figure 6. 


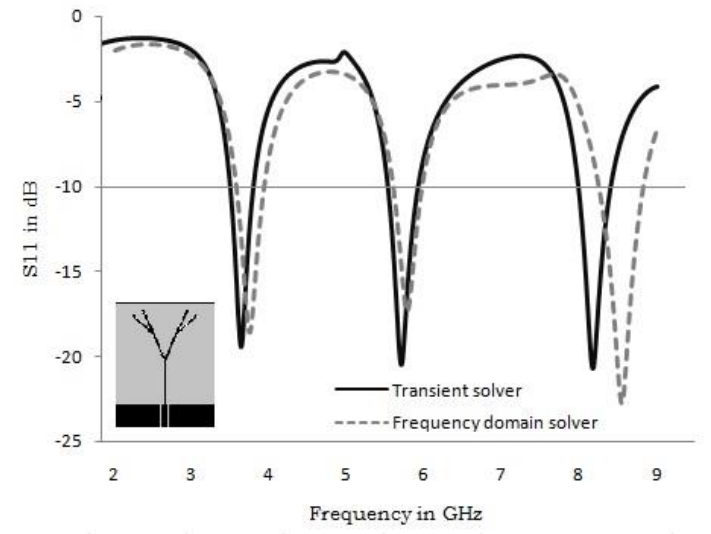

Figure. 5. Simulated $S_{11}$ vs. Frequency graph of reader antenna based on transient and frequency domain solver Directivity Abs (Phi=90)

Directivty Abs (Phi $=0$ )

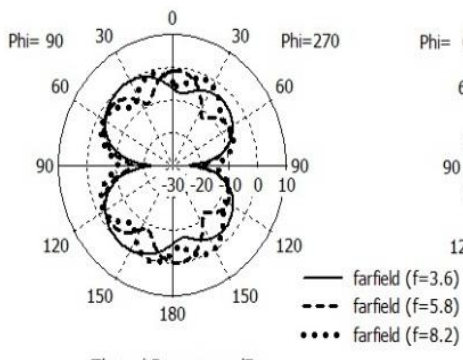

Theta / Degree vs. dB

(a)

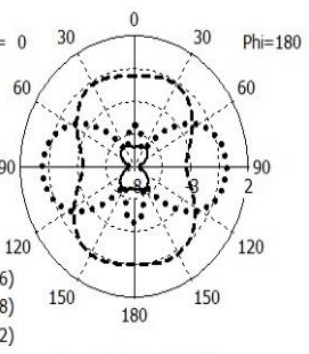

Theta / Degree vs. dB

(b)

Figure 6. Radiation results of RFID Reader.
(a) $\mathrm{H}$ field (b) E field
b) Tag antenna

The simulated result of $S_{11}$ vs. frequency chart of tag antenna is presented in Figure 7 . First frequency is $\mathrm{f}_{1} 3.9 \mathrm{GHz}$, whose $\mathrm{S}_{11}$ occurs at $-17.12 \mathrm{~dB}$ and obtained bandwidth $(-10 \mathrm{~dB})$ at $238 \mathrm{MHz}$ and bandwidth percentage of 6.1.The next frequency is $5.9 \mathrm{GHz}, \mathrm{S}_{11}$ falls with $19.69 \mathrm{~dB}$ and the corresponding bandwidth is $181 \mathrm{MHz}$ with bandwidth percentageof 3 . The last frequency is giving $S_{11}$ value of $-20.31 \mathrm{~dB}$ with a bandwidth $(-10 \mathrm{~dB})$ of $310 \mathrm{MHz}$ and 3.7 bandwidth percentage. The Figure 7 shows the simulated results of transient domain solver and frequency domain solvers encompassing high association with each other results. 


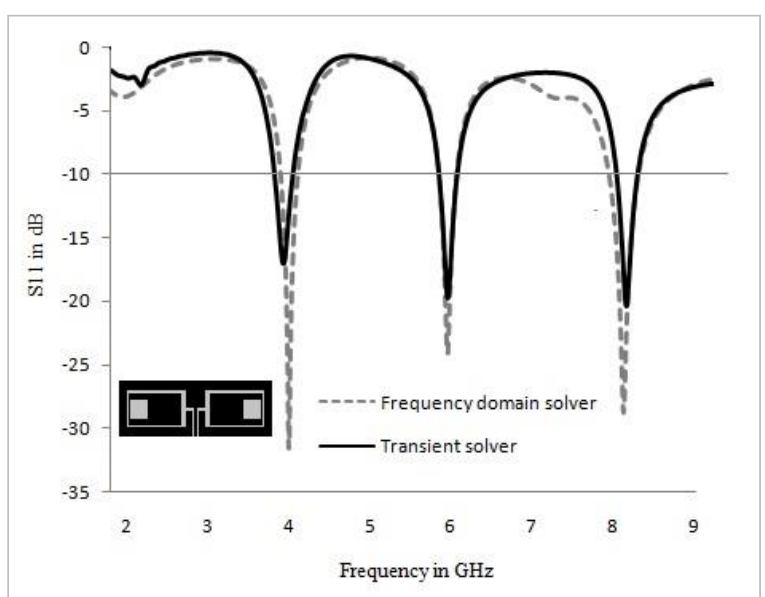

Figure. 7. Simulated $S_{11}$ vs. Frequency graph of tag antenna based on transient and frequency domain solver

The tag antenna VSWR bandwidth (measured at VSWR=2) is given as $255 \mathrm{MHz}$ atf ${ }_{1}, 230$ $\mathrm{MHz} \mathrm{f}_{2}$ and $285 \mathrm{MHz}$ at $\mathrm{f}_{3}$ and the corresponding $\mathrm{E}$ and $\mathrm{H}$ plane pattern is presented in Figure 8.

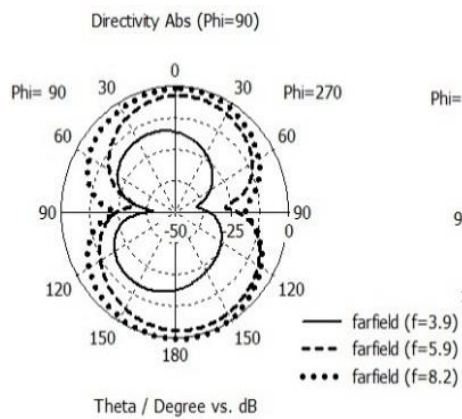

(a)

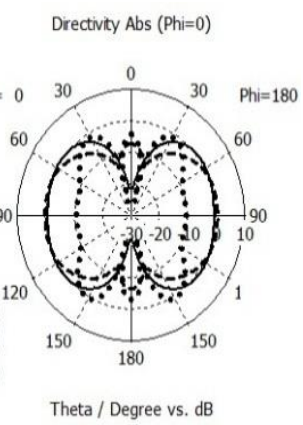

(b)

Figure 8. Radiation results of RFID Tag antenna.

(a) $\mathrm{H}$ field (b) E field

\section{Fabrication and Measurement of prototype}

\section{Prototype of Reader and Tag antenna}

The RFID Reader and Tag antenna was fabricated post simulation and analysis, with FR4 material as substrate. The authors preferred a chip-less design and testing. The simulation was carried out in transient solver and frequency domain solvers based on waveguide port. Practically, the SMA connectors were connected to the edge of the antennas and excitation was provided. The measurement of $S_{11}$ characteristics was executed by Agilent E8363B VNA. The prototype of both reader and tag antenna are shown in the Figures 9. Figure 10\& 11, indicating the comparison result of measurement and simulated $S_{11}$ characteristics of reader antenna. 


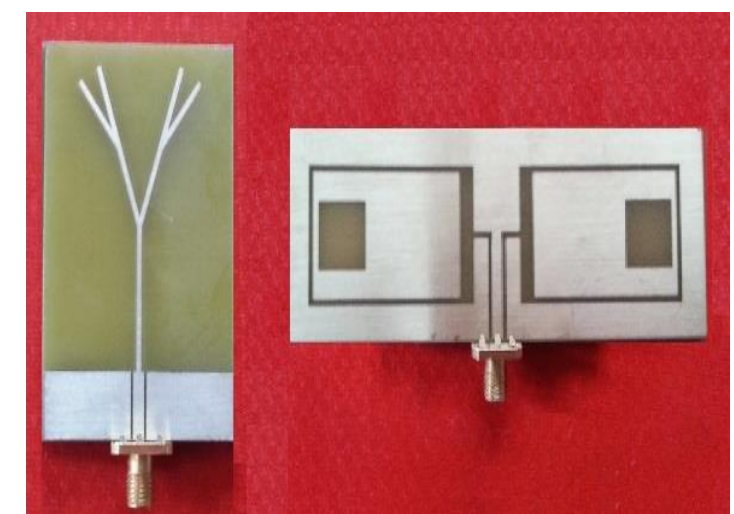

Figure 9. Fabricated prototypes of RFID Reader and Tag

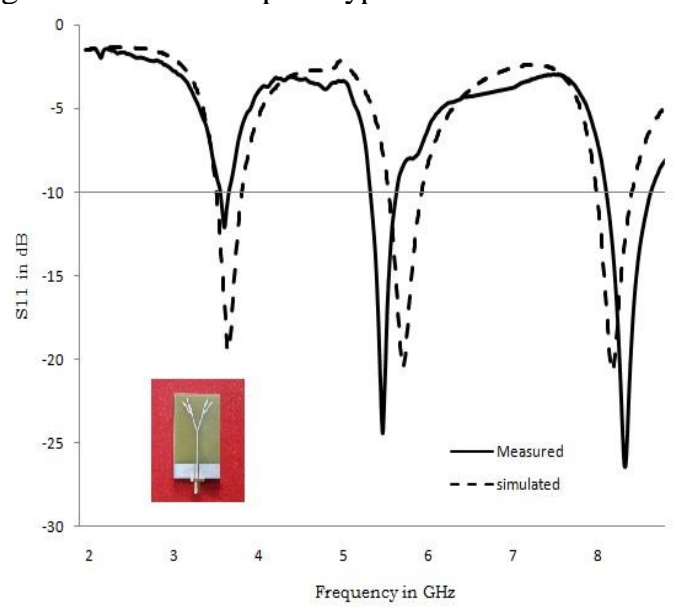

Figure. 10. Measured result and Simulated results of $S_{11}$ vs. Frequency graph of reader

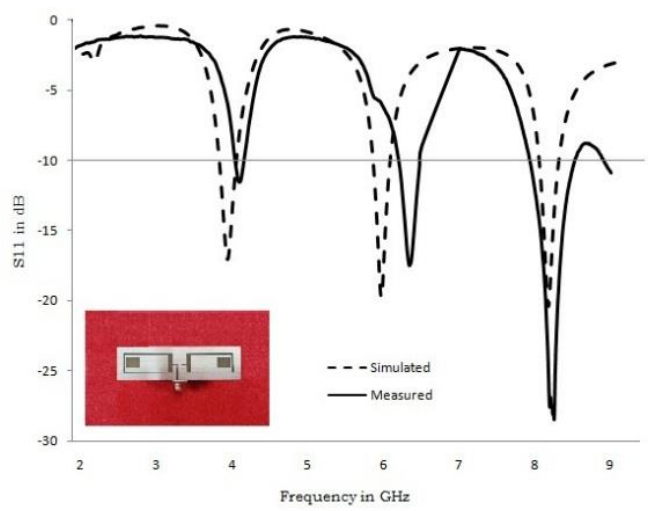

Figure. 11. Measured result and Simulated results of $S_{11}$ vs. Frequency graph of tag 
Measured results and simulated $\mathrm{S}_{11}$ characteristics arecompared andindicatedin Figures 10 and 11. The advantage of the CPW structure is that, at the same plane both ground and conductors are fabricated. It is used as a feeder element for antennas.

Calculation of Read range

The Friis Transmission Equation is used to evaluate the antenna parameters encompassing the gain of reader and tag antenna, received and transmitted power $P_{R}$ and $P_{T}$, operating frequency $\mathrm{f}_{\mathrm{c}}$, wavelength $\lambda$,read range $R$, velocity of light $c$, the gain of receiver and transmitter antenna $G_{r}$ and $G_{t}$.

Power Density can be calculated from

$p=\frac{P_{T}}{4 \pi R^{2}}$

Considering the transmit antenna gain $\mathrm{G}_{\mathrm{t}}$, then the power density becomes

$p=\frac{P_{T}}{4 \pi R^{2}} G_{t}$

Assume the Effective Aperture of the antenna then the received power becomes

$P_{R}=\frac{P_{T} G_{t} G_{r} \lambda^{2}}{(4 \pi R)^{2}}$

The read range can be calculated by above Friis Transmission equation

The reader and tag antenna read range is calculated by keeping $3 \mathrm{dBi}$ gain as a reference, $4 \mathrm{~W}$ as the transmitting powerand $1 \mathrm{~mW}$ as detectable least power. The calculated read range of both reader and tag antenna for various operating frequency is indicated in Table 1.

Table 1. Read Range Chart

\begin{tabular}{|l|l|l|l|}
\hline $\begin{array}{c}\text { Operating } \\
\text { Frequency } \\
(\mathbf{G H z})\end{array}$ & $\begin{array}{l}\text { Type of } \\
\text { Antenna }\end{array}$ & $\begin{array}{c}\text { Antenna } \\
\text { gain } \\
(\mathbf{d B i})\end{array}$ & $\begin{array}{c}\text { Calculated } \\
\text { Read range } \\
(\mathbf{c m})\end{array}$ \\
\hline 3.6 & Reader & 3.4 & 87.5 \\
\hline 3.9 & Tag & 3.9 & 85.6 \\
\hline 5.8 & Reader & 2.7 & 50.1 \\
\hline 5.9 & Tag & 3.0 & 51.02 \\
\hline 8.2 & Reader & 2.6 & 35.06 \\
\hline 8.2 & Tag & 2.2 & 33.48 \\
\hline
\end{tabular}

\section{Conclusion}

Fractal antennas are designed to conserve low profile, attain multiband and be miniature in size. In this publication RFID Reader and Tag antennas are introduced using fractal geometry. At $-10 \mathrm{~dB}$ bandwidth, the obtained results of RFID tag antenna of $238 \mathrm{MHz} @$ $3.9 \mathrm{GHz}, 181 \mathrm{MHz} @ 5.9 \mathrm{GHz}, 310 \mathrm{MHz} @ 8.2 \mathrm{GHz}$. Similarly, the results of the reader antenna of $248 \mathrm{MHz} @ 3.6 \mathrm{GHz}, 398 \mathrm{MHz} @ 5.8 \mathrm{GHz}, 405 \mathrm{MHz} @ 8.2 \mathrm{GHzat}-10 \mathrm{~dB}$ bandwidth. The highest RFID reader antenna read range is $87.5 \mathrm{~cm}$ and similarly, obtained maximum read range is $85.6 \mathrm{~cm}$ by the tag antenna

\section{References}


[1] Hui Li, Le Kang, Feng Wei, Yuan-Ming Cai, and YingZeng Yin, "A Low-Profile Dual-Polarized Microstrip AntennaArray for Dual-Mode OAM Applications," IEEE Antennas and Wireless Propagation Letters, Vol. 16, pp. 3022-3025, 2017

[2] Zhao Zhou;Zhaohui Wei;Zhaoyang Tang;Yingzeng Yin, "Design and Analysis of a Wideband Multiple-Microstrip Dipole Antenna with High Isolation," IEEE Antennas and Wireless Propagation Letters, Volume: 18, Issue: 4, pp. 722 - 726, 2019.

[3] O. Hussein, K. Al Shamaileh, A. Sahu, B. Keneni, and V. Devabhaktuni, "Optimization of Miniaturized Single-and Multi - band CPW - based Matching Transformers for RF Circuitry on LCP Substrates," no. 1, pp. 8-10, 2017.

[4] D. Inserra, W. Hu, G. Wen, and S. Member, "Antenna Array Synthesis for RFID-based Electronic Toll Collection,” IEEE Trans. Antennas Propag., vol.66, Issue 9, pp 4596 - 4605, 2018

[5] Zijian Shao and Yue Ping Zhang, "Miniaturization of Differentially-Driven Microstrip Planar Inverted F Antenna", IEEE Transactions on Antennas and Propagation, Volume: 67, Issue: 2, pp. $1280-1283,2018$

[6] E. Pazmi, V. Juan, J. Rosero, and D. Pozo, "Passive Chipless RFID Tag Using Fractals : A Design Based Simulation", 2017 IEEE Second Ecuador Technical Chapters Meeting (ETCM), Electronic ISBN:978-1-5386-3894-1, 2017

[7] M. M. Sharma, P. Kaith, M. Jangid, and S. Singhal, "Decagonal Sierpinski UWB Fractal Antenna with Asymmetric CPW-Feed and ModifiedGround," 2019 IEEE Indian Conference on Antennas and Propogation (InCAP), DOI:10.1109/InCAP47789.2019.9134647, 2019.

[8] H. Sun and S. Sun, "A Novel Reconfigurable Feeding Network for Quad-Polarization-Agile Antenna Design,”, IEEE Trans. Antennas Propag., , doi: 10.1109/TAP.2015.2497350, vol. 64, no. 1, pp. 311-316, 2016.

[9] Constantine A. Balanis, “Antenna Theory”, Second Edition, Wiley student edition.

Author Bibliography

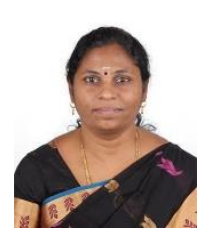

Mrs. ChitraVaradhan, received Bachelor degree in Electronics and Communication Engineering from Regional Engineering College (NIT- affiliated with Bharathidhasan University) Trichy in 1996 and completed Master of Engineering in College of Engineering, Anna University, Guindy, Chennai in 2008. Currently pursuing PhD in Fractal Antennas in BIHER [Bharath Institute of Higher Education \& Research] Chennai, Tamil Nadu, India.

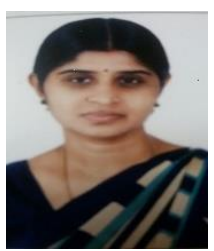

Dr S. Arulselvi, working as an Associate Professor, in BIHER [Bharath Institute of Higher Education \& Research] Chennai, Tamil Nadu, India. Areas of specialization include Networking and communications. Currently guiding Mrs ChitraVaradhan in the area of Fractal Antennas. 